\title{
Perceived Stress, Emotional Intelligence and Self-efficacy among Nursing Students during the Covid-19 Pandemic
}

\author{
Jesin Varughese, Dr. Rema M.K. \\ * Psychology, Kristu Jayanti College Bangalore. \\ DOI: 10.29322/IJSRP.11.04.2021.p11225 \\ http://dx.doi.org/10.29322/IJSRP.11.04.2021.p11225
}

\begin{abstract}
Present study examined the relationship between perceived stress, emotional intelligence and self-efficacy among nursing students during the COVID-19 Pandemic. The questionnaires used were the PSS (Perceived stress scale) to measure perceived stress, the Emotional intelligence scale to measure emotional intelligence and SES (Self-efficacy scale) to measure self-efficacy, the data has collected from 120 nursing students from south India. Descriptive correlational research design was used and convenient sampling technique was employed to select the sample. The results showed that there is a positive correlation found between emotional intelligence and self-efficacy among nursing students during the pandemic. On the other hand there is no correlation found between emotional intelligence and Perceived stress. Also self-efficacy and Perceived stress is not found to be correlated among nursing students which shows the emotional intelligent and self-efficacy is not helping them to manage stress during the pandemic. Meanwhile according to the finding the emotional intelligence would help them to have more self-efficacy.
\end{abstract}

Index Terms: COVID-19 Pandemic, Emotional Intelligence, Nursing Students, Perceived Stress, Self-efficacy.

\section{INTRODUCTION}

Nursing Education would help us to professional nurses. They will have theoretical as wells practical training. Nursing education should perpetually evolve the needs the wants of students, and provide a solid foundation for consequent practice (Lindeman, 2000).

The coronavirus disease (COVID-19) pandemic, which began in China in December 2019 and spread around the world, it has affected each and everyone in the world. The impact of the pandemic is huge. There are negative physical as well as psychological effects. The extent of anxiety will increase even additional as a result of the outbreak and ending method are unknown (Tutku et al., 2020).

Perceived stress is that the feelings or thoughts that a person has concerning what proportion stress they're beneath at a given point in time or over a given time period. In the COVID-19 pandemic situation nursing students had to deal with practical training and online classes. Emotional intelligence could be a variety of social intelligence that involves the power to monitor one's own and others' emotions, to discriminate among them, and to use the information to guide one's thinking and actions (Salovey \& Mayer, 1990). Emotional intelligence would help us to have the awareness and control over our behavior. It helps us to have both personal and professional success. Self-efficacy is, according to psychologist Albert Bandura, a personal judgment of "how well one can execute courses of action required to dealing with the realities and complexities of practice might be buffered by emotionally competent graduates who can handle occupational stress"(Bandura, 1982). High self-efficacy helps produce feelings of serenity in approaching tough tasks and activities.

\subsection{Need for the study}

In this COVID 19 pandemic situation nurses have played a crucial role in fighting with it. The colleges started online categories conjointly the clinical observe of nursing students in hospitals have also been interrupted. As a result a lot of nursing education consists of clinical practices; students might have been concerned regarding being inadequate in clinical skill development. Nursing students are the future frontline workers of pandemics and also their mental health is very important as they play a vital role 
in our society. There are very less research done on relation between perceived stress, emotional intelligence and self-efficacy. This research was administered since it had been thought that particularly for nursing students to encounter the pandemic method for the primary time, and this might had an effect on their Perceived Stress, Emotional Intelligence and Self-efficacy. So, this study aimed to work out the relation between perceived stress, emotional intelligence and self- efficacy of nursing students throughout the pandemic.

\subsection{Review of Literature}

Maia and Dias (2020) analyzed whether the amount of depression, anxiety and stress in university students have modified throughout the period of the pandemic compared with the previous normality. This study comprised 2 groups, within which sample- 1 consists of 460 subjects with a mean age of 20.14 and sample-2, 159 subjects with a mean age of 20.40. All the participants completed a socio-demographic questionnaire and were assessed by way of the Anxiety, Depression and Stress Scales. The students evaluated throughout the period of the pandemic given considerably higher levels of anxiety, depression and stress, compared with students in erstwhile, normal times. The results recommend that the pandemic contains a negative psychological result on students. It is vital to continue exploring the implications of the pandemic on students' mental health, in order that its effects are often prevented, or at least mitigated.

A study was done to see the extent of cognitive failure, perceived stress and self-efficacy among graduate nursing students, moreover as, to analyze the connection between these variables. A descriptive correlational style was used for this study. The study was conducted at college of Nursing, Alexandria University, Egypt. Subjects: These comprised a hundred graduate students. Sociodemographic and academic information structured faculty, the cognitive Failure questionnaire (CFQ), Perceived Stress Scale (PSS) and General Self-Efficacy Sub-Scale. Results of the study showed that, the bulk of the studied students had moderate to high level of cognitive failure and moderate level of perceived stress. Additionally, the majority of them had moderate to high level of self-efficacy. A statistical important positive relation between cognitive failure and perceived stress was found. Meanwhile, statistical important negative correlations between light failure, perceived stress and self-efficacy were found (Elsayed et al., 2020).

Rebello (2019) have evaluated the relationship between emotional intelligence (EI), coping mechanisms and perceived stress in undergraduate nursing students. The experimental design was quantitative non-experimental descriptive. The sample was collected from the undergraduate nursing students. The students that selected to participate took a survey that enclosed data collection on demographics, EI scores, perceived stress and cope mechanisms. The findings show that the emotional intelligence and perceived stress is negatively correlated. This result found that as emotional intelligence will increase, perceived stress within the undergraduate nursing student decreases. It shows that students with lower emotional intelligence $(\bar{x}=116.7)$ utilize maladaptive coping mechanism, whereas with higher EI $(\bar{x}=131.05)$ and who had lower perceived stress scores $(\bar{x}=19.35)$ typically utilized adaptive coping tend to utilize adaptation coping mechanisms. PSS and coping mechanism also had a statistically significant relationship. That is, while maladaptive coping was used in students who had higher perceived stress $(\bar{x}=27.143)$.

A study investigated the emotional intelligence (EI), self-efficacy, and clinical communication ability of clinical nurses to explore the correlation among these three variables, and verify the mediating effect of self-efficacy on relationship between EI and communication skills. A total of 865 nurses were recruited and investigated using Wong and Law's Emotional Intelligence Scale, General Self-Efficacy Scale, and nurse clinical communication scale. The scores for EI and self-efficacy of nurses were $14.23 \pm 2.61$ and $25.36 \pm 5.67$, respectively, which were lower than the international norm $(\mathrm{p}<0.01)$. The score for clinical communication ability of nurses was $4.14 \pm 0.53$. The clinical communication competency of nurses was positively correlated with EI and general selfefficacy. Furthermore, self-efficacy played an intermediary role between EI and clinical communication commitment. Nursing administrators can improve the clinical communication ability of nurses by enhancing their self-efficacy and Emotional Intelligence (Zhu et al., 2016).

\section{METHODS}

\subsection{Statement of the problem}

Is there any relationship between perceived stress, emotional intelligence and self- efficacy of nursing students during the pandemic?

\subsection{Research Design}

Descriptive correlational research design was followed in this study

\subsection{Objectives}

1. To assess Perceived Stress, Emotional Intelligence and Self-efficacy of Nursing students during the pandemic.

2. To examine the relationship between Perceived Stress and Emotional intelligence of nursing students during the pandemic.

3. To examine the relationship between Perceived Stress and Self-Efficacy of nursing students during the pandemic.

4. To examine the relationship between Emotional Intelligence and Self-Efficacy of nursing students during the pandemic

This publication is licensed under Creative Commons Attribution CC BY.

http://dx.doi.org/10.29322/IJSRP.11.04.2021.p11225

WwW.ijsrp.org 


\subsection{Hypothesis}

Null Hypothesis $\mathrm{H}_{0} 1$ : There will be no significant relationship between Perceived

Stress and Emotional Intelligence of nursing students during the pandemic.

Alternative Hypothesis $\mathrm{H}_{1} 1$ : There will be a significant relationship between Perceived Stress and Emotional Intelligence of nursing students during the pandemic

Null Hypothesis $\mathrm{H}_{0} 2$ : There will be no significant relationship between Perceived Stress and Self-Efficacy of nursing students during the pandemic.

Alternative Hypothesis $\mathrm{H}_{1} 2$ : There will be a significant relationship between Perceived Stress and Efficacy of nursing students during the pandemic.

Null Hypothesis $\mathrm{H}_{0} 3$ : There will be no significant relationship between Emotional intelligence and Self-efficacy among nursing students during the pandemic.

Alternative Hypothesis $\mathrm{H}_{1} 3$ : There will be a significant relationship between Emotional intelligence and Self- efficacy among nursing students during the pandemic.

\subsection{Sampling Procedure}

The study aims at measuring the stress among nursing students and studying relation of this stress on their emotional intelligence and self-efficacy in the pandemic. Convenient sampling technique were used The Sample size is 120 Nursing students. Data's are collected from different parts of South India (Kerala, Tamil Nadu and Karnataka) and from students studying in different institutions.

- An inclusion criterion is nursing students in between the age of 18 to 24 years.

- The Exclusion criterion is the nursing students who have just entered their studies as freshman.

\subsection{Tool used for the study}

\section{a. $\quad$ Perceived Stress Scale (PSS)}

The Perceived Stress Scale (PSS) (Cohen et al., 1983) is one of the more popular tools for measuring psychological stress. It is a self-reported questionnaire that was designed to measure "the degree to which individuals appraise situations in their lives as stressful. Reliability of PSS10: Cronbach's alpha $=0.78$. Validity of PSS10: Correlates in a predicted way with other measure of stress (job responsibilities scale, life events scales). The PSS-10 scores are obtained by reversing the scores on the four positively stated items, e.g. $0=4,1=3,2=2,3=1$ and $4=0$ and then sum across all 10 items. Items $4,5,7$ and 8 are the positively stated items. The higher the PSS score, the more likely it is that the individual will perceive that environmental demands exceed their ability to cope.

\section{b. Emotional Intelligence Self-assessment Tool}

Emotional Intelligence Self- Assessment Tool is a 20 item scale with four components: Self-Awareness, Self-Management, Social Awareness, and Relationship Management. Scaling: It is a 5- point Likert scale, $1=$ never; $2=$ rarely; $3=$ sometimes; $4=$ usually; $5=$ always.

\section{c. Self-Efficacy Scale}

Self-Efficacy is the belief in one's capability to organize and execute the course of action required to manage prospective situations. Self-efficacy scale given by Ralf Schwarzer and Matthias Jerusalem, 1993 is used. The reliability of the scale was established by using test-retest method and it is found to be 0.64 and validity of the scale computed is 0.80 . It consists of ten statements. The range is from 10 to 40 points. The minimum and maximum possible scores on self-efficacy scale ranges from 10-40. Low score indicates low self-efficacy high score indicates high self-efficacy.

\subsection{Ethical Consideration}

Informed consent was obtained from each student after explanation of the study purpose and importance. Confidentiality was ensured and they were also informed that their information would be used only for research purpose. The Right to refuse participation on the study was ensured.

\subsection{Statistical Techniques}

This publication is licensed under Creative Commons Attribution CC BY.

http://dx.doi.org/10.29322/IJSRP.11.04.2021.p11225

WwW.ijsrp.org 
The Research question is answered using descriptive statistics and correlation analysis. Descriptive statistics (mean and standard deviation) were used to describe characteristics of the subjects including perceived stress, self-efficacy and emotional intelligence. The descriptive correlation analysis is used and spearman's correlation test is used to find out the correlation between is variables. The statistical methods used in this research were descriptive statistics and Spearman's correlation using Statistical Package for Social Sciences (SPSS).

\section{Results and Discussion}

The aim of the present study was to examine the relation between perceived stress emotional intelligence and self-efficacy in nursing students during the pandemic. The objectives of the study are to assess perceived stress, emotional intelligence and selfefficacy and to determine the relationship between these variables. The null Hypothesis states that there will no relationship between is variables. The data analysis of perceived stress, emotional intelligence and self- efficacy of nursing students, as well as the description of the descriptive and correlational analysis of the sample that participated in the study will be discussed.

Table 1: Socio-demographic details of the sample.

\begin{tabular}{|l|l|l|l|}
\hline Characteristics & & Number & Percentage \\
\hline Sample size & & 120 & \\
& & & \\
\hline Age & 18 to 20 years & 80 & $66.6 \%$ \\
\hline & 20 to 23 years & 40 & $33.3 \%$ \\
\hline Gender & Male & 4 & $3.33 \%$ \\
\hline & Female & 116 & $96.6 \%$ \\
\hline
\end{tabular}

Table 1 shows the socio-demographic details of the sample. The sample size is 120 nursing students. In the 120 sample of students was found to be mainly female $(n=116$, and $96.6 \%$. with males making up a smaller amount of the data collected $(n=4)$ that' is $3.33 \%$ of the total sample size. Participant's ages ranged from 18 to 23 years. In 18 to 20 years there are 80 students, that 'is $66.6 \%$ and 40 students were of the age 21 to 23 years that is $33.3 \%$ for the total population.

Table 2: Descriptive statistics

\begin{tabular}{|l|l|l|}
\hline Variables & Mean & Std.D \\
\cline { 2 - 4 } & Statistic & Statistic \\
\hline The Perceived Stress Scale & 21.43 & 5.203 \\
\hline $\begin{array}{l}\text { Emotional Intelligence Self- } \\
\text { Assessment Tool }\end{array}$ & 71.93 & 10.744 \\
\hline Self-efficacy scale & 29.95 & 4.933 \\
\hline
\end{tabular}

Table 2 shows the descriptive statistics used interpret the result of data perceived stress, emotional intelligence, and selfefficacy. Descriptive statistics table shows the mean and standard deviation of the variables. The mean and standard deviation of perceived stress is 21.43 and 5.203 respectively, which indicated average level of perceived stress in the sample. The mean and standard deviation of emotional intelligence is 71.9 and 10.744 respectively, which indicates high level of emotional intelligence in the sample. The mean and standard deviation of self-efficacy is 29.95 and 4.933respectively, indicating average level of self-efficacy in the sample.

Table 3: Correlation between perceived stress and emotional intelligence

\begin{tabular}{|l|l|l|}
\hline & \multicolumn{1}{|c|}{ Emotional intelligence } \\
\hline \multirow{3}{*}{ Perceived Stress } & $\begin{array}{l}\text { Correlation Coefficient } \\
\left(\mathrm{r}_{\mathrm{s})}\right.\end{array}$ & .082 \\
\cline { 2 - 3 } & $\mathrm{p}$-value & .372 \\
\hline
\end{tabular}

This publication is licensed under Creative Commons Attribution CC BY. 
$\mathrm{H}_{0} 1$ : There will be no significant relation between Perceived Stress and Emotional Intelligence of nursing students during the pandemic.

$\mathrm{H}_{1} 1$ : There will be a significant relation between Perceived Stress and Emotional Intelligence of nursing students during the pandemic

The correlation between the perceived stress and emotion intelligence were measured. Table 3 indicates the Spearman's correlation result and it shows that there is no correlation between perceived stress and emotional intelligence $\left(\mathrm{r}_{\mathrm{s}}=.082\right)$ which is not significant $(\mathrm{p}=.372)$. Thus null hypothesis is accepted. There is no significant relation between Perceived Stress and Self-Efficacy of nursing students during the pandemic. That is there is no association between emotional intelligence and increased level stress in the pandemic There is a supporting study which has analysed whether the levels of depression, anxiety and stress in university students have changed during the period of the pandemic compared with the previous normality(Maia \& Dias, 2020). The result might have deviated from the previous normality studies it might be because of the impact of pandemic situation among nursing students. However, there are a contradictory study which has evaluated the relationship between emotional intelligence (EI), coping mechanisms and perceived stress in undergraduate nursing students. The findings show that there is a negative relationship between emotional intelligence and perceived stress. This result found that as emotional intelligence increases, perceived stress in the undergraduate nursing student decreases(Rebello, 2019). This contradictory study has done before the COVID 19 pandemic situation which shows that those who have high emotional intelligence is also tend to have increased stress level in this pandemic situation. In this study there is no correlation between the emotional intelligence and perceived stress. This shows the strong impact of pandemic situation among nursing students.

Table 4 : Correlation between perceived stress and self-efficacy

\begin{tabular}{|l|l|l|}
\hline & \multicolumn{1}{|c|}{ Self-Efficacy } \\
\hline \multirow{2}{*}{ Perceived Stress } & $\begin{array}{l}\text { Correlation Coefficient } \\
\left(\mathrm{r}_{\mathrm{s}}\right.\end{array}$ & -.005 \\
\cline { 2 - 3 } & $\mathrm{p}$-value & .958 \\
\hline
\end{tabular}

$\mathrm{H}_{0} 2$ : There will be no significant relation between Perceived Stress and Self-Efficacy of nursing students during the pandemic. $\mathrm{H}_{1}$ 2: There will be a significant relation between Perceived Stress and Self-Efficacy of nursing students during the pandemic.

The correlation between the variables, perceived stress and self-efficacy were measured. Table 4 indicates the Spearman's correlation result and it shows that there is no correlation between perceived stress and self-efficacy $\left(r_{s}=-.005\right)$ which is not significant with sig value $(\mathrm{p}=.958)$. Thus Null hypothesis is accepted. There is no significant relation between Perceived Stress and SelfEfficacy of nursing students during the pandemic. That is the self-efficacy has no association with increased level stress in the pandemic and perceived stress will not affect the self-efficacy of the nursing students. There is a supporting study which has analysed extent of cognitive failure, perceived stress and self-efficacy among graduate nursing students and they have found statistical significant negative correlations between cognitive failure, perceived stress and self-efficacy were found (Elsayed et al., 2020)

Table 5: Correlation between self-efficacy and emotional intelligence

\begin{tabular}{|l|l|l|}
\hline \multirow{3}{*}{ Self-efficacy } & \multicolumn{1}{|c|}{ Emotional intelligence } \\
\hline & $\begin{array}{l}\text { Correlation Coefficient } \\
\left(\mathrm{r}_{\mathrm{s})}\right.\end{array}$ & $.558^{* *}$ \\
\cline { 2 - 3 } & $\mathrm{p}$-value & .000 \\
\hline
\end{tabular}

Note: **. Correlation is significant at the 0.01 level (2-tailed).

$\mathrm{H}_{0}$ 3: There will be no significant relation between Emotional Intelligence and Self-Efficacy of nursing students during the pandemic. $\mathrm{H}_{1} 3$ : There will be a significant relation between Emotional Intelligence and Self-Efficacy of nursing students during the pandemic.

The correlation between emotion intelligence and self-efficacy were measured. Table 5 indicates the Spearman's correlation result and it shows that there is a moderate positive correlation between emotional intelligence and self-efficacy $\left(\mathrm{r}_{\mathrm{s}}=.558\right)$ at a significant level of $0.01(\mathrm{p}=.001)$. The null hypothesis is rejected and alternative hypothesis is accepted. There is a significant relation between Emotional Intelligence and Self-Efficacy of nursing students during the pandemic. That is those who have This publication is licensed under Creative Commons Attribution CC BY. 
more emotional intelligence are also tending to have increased level of self-efficacy in the pandemic. As the findings say there is a constant positive correlation between emotional intelligence and self-efficacy is found in many studies as well. A similar study have supported the finding which investigated the emotional intelligence (EI), self-efficacy, and clinical communication ability of clinical nurses to explore the correlation among these three variables, and verify the mediating effect of self-efficacy on relationship between emotional intelligence and communication skills. The clinical communication competency of nurses was positively correlated with EI and general self-efficacy(Zhu et al., 2016).

\section{Summary and Conclusion}

\subsection{Summary}

Present study aimed to examine the relationship between perceived stress, emotional intelligence and self- efficacy of nursing students during the pandemic. The sample size is 120 nursing students from different institution in south India. The result shows there is a no relation between emotional intelligence and perceived stress in the pandemic which shows the emotional intelligent is not helping them to manage stress during the pandemic. There is no correlation is found between self-efficacy and perceived stress in the pandemic situation which shows that when they have more perceived stress, their self-efficacy is not affected. There is a positive correlation between self-efficacy and emotional intelligence showing an increase in emotional intelligence will have an increase in self-efficacy.

\subsection{Major Findings of the Study}

The COVID 19 pandemic situation has a huge stressful impact on nursing students as they tend to have increased level of stress even though they have moderate high level of emotional intelligence. The importance of self-efficacy and emotional intelligence is that it help is manage stress but in this study maybe due to pandemic situation there is no association found between these variables and perceived stress which shows the importance of the mental health of nursing students. They should have much more importance which would alleviate distress and increase the wellbeing as healthcare professionals in future. The emotional intelligence and selfefficacy has a positive correlation which shows that the increase in emotional intelligence will also increase the self-efficacy.

\subsection{Implications}

The COVID-19 pandemic has affected not only nursing students but the entire world. Our study found that the perceived stress level of nursing students does not have association with emotional intelligence and self-efficacy during the pandemic. The perceived stress is not affecting the emotional intelligence and self-efficacy so it will not affect their profession. But it is important to know, if the perceived stress is not decreasing even after pandemic they should have interventions for nursing students which brings the ability to cope with perceived stress with effective measure as it shows that even the emotional intelligence and self-efficacy has helped them to cope with stress before the pandemic. Thus, in dealing with stress, nursing students will contribute to helping individuals in society as they are the future frontline workers of pandemic. We found that there is a positive association with emotional intelligence and self-efficacy. So for the future nursing professionals to have high level of self-efficacy we can provide them training to increase the emotional intelligence which would help them to increase the self-efficacy as well.

\subsection{Limitation}

1. The sample size was confined to a limited population specifically nursing students from south India. Therefore, it is not possible to generalize the results to a larger population.

2. Gender was not taken into consideration.

3. In extrapolating the results, it should also be taken into consideration that the sample included more female nurses than males, a characteristic trait of the nursing profession in south India.

4. Reliability and validity of emotional intelligence scale is not found.

5. Data collection was done by filling in online questionnaires, and this procedure could have been subject to social desirability by the participants in the study and have partly conditioned the results.

6. The result of the study can be a new study as there is no much review of literature supporting the positive relation between the emotional intelligence and self-efficacy with perceived stress.

\subsection{Suggestions for Future Studies}

1. We can continue studying the relationship between emotional intelligence, self-efficacy and perceived stress, keeping in mind contextual, age and gender variables.

This publication is licensed under Creative Commons Attribution CC BY.

http://dx.doi.org/10.29322/IJSRP.11.04.2021.p11225

WwW.ijsrp.org 
2. We can also analyse further study the relationship between emotional intelligence, self-efficacy and perceived stress with the role of personality variables and self-esteem.

3. Future lines of research can propose in which personal and contextual variables can be considered.

4. Various interventional studies need to be done to know the effectiveness of various techniques which can help to manage the stress level among nursing students and for betterment of country.

\section{REFERENCES}

[1] Bandura, A. (1982). Self-efficacy mechanism in human agency. American Psychologist, 37, 122-147.

[2] Cohen, S., Kamarck, T., \& Mermelstein, R. (1983). A global measure of perceived stress. Journal of Health and Social Behavior, 385-396.

[3] Elsayed, M., Ghazi, G., \& Abdelaal, H. (2020). Cognitive Failure, Perceived Stress and Self-Efficacy among Graduate Nursing Students, Alexandria University, Egypt.

[4] Lindeman, C. A. (2000). The future of nursing education. Journal of Nursing Education, 39(1), 5-12.

[5] MAIA, B. R., \& DIAS, P. C. (2020). Anxiety, depression and stress in university students: the impact of COVID-19. Estudos de Psicologia (Campinas), 37.

[6] Rebello, M. (2019). THE RELATIONSHIP BETWEEN EMOTIONAL INTELLIGENCE, PERCEIVED STRESS AND COPING MECHANISMS IN THE UNDERGRADUATE NURSING STUDENT.

[7] Salovey, P., \& Mayer, J. D. (1990). Emotional Intelligence. Imagination, Cognition and Personality, 9(3), 185-211. https://doi.org/10.2190/DUGG-P24E-52WK$6 \mathrm{CDG}$

[8] Tutku, E., ILIMAN, E., \& DÖNMEZ, E. (2020). Bireylerin Sağlik Anksiyetesi Düzeyleri İle Covid-19 Salgini Kontrol Algisinin Karşilaştirilmasi. Uluslararası Sağlık Yönetimi ve Stratejileri Araştırma Dergisi, 6(1), 139-154.

[9] Zhu, B., Chen, C.-R., Shi, Z.-Y., Liang, H.-X., \& Liu, B. (2016). Mediating effect of self-efficacy in relationship between emotional intelligence and clinical communication competency of nurses. International Journal of Nursing Sciences, 3(2), 162-168. https://doi.org/https://doi.org/10.1016/j.ijnss.2016.04.003

\section{AUTHORS}

First Author - JESIN VARUGHESE, Student, MSc. Psychology at Kristu Jayanti College, Bangalore. jesin.j132@gmail.com

\section{Second Author - Dr. Rema MK.}

M.A., Ph.D., Certification in Counseling Supervision. Assistant Professor at Kristu Jayanati College Bangalore, dr.rema@kristujayanti.com 